\title{
Knowledge intensive business services and long term growth
}

\author{
Benoît Desmarchelier, Faridah Djellal, Faïz Gallouj
}

December 27, 2011

\begin{abstract}
The goal of this paper is to (re)assess the relationship between knowledge intensive business services (KIBS) and the economic growth. Taking into account various conflicting relationships between KIBS and growth, we build a multi agent-based system involving industrial firms, consumer-services firms, consumers, KIBS firms and a banking system. Our main result is that KIBS can be regarded as an engine for the economic growth and that they operate as a substitute for the material capital accumulation. Nevertheless, material capital accumulation always appears as a significant factor of economic growth.
\end{abstract}

\section{Introduction}

Knowledge intensive business services (KIBS) can be defined, in general terms, as activities in which knowledge is both the main input and the main output (Gallouj, 2002 [22]). They mainly consist of survey, consultancy, research and engineering activities targeted at businesses (for classifications of these activities, see Miles et al., 1995 [32]; Hertog, 2000 [14]; Muller and Zenker, 2001 [33]). KIBS firms play an important and increasing role in the diffusion of knowledge between agents in contemporary economies (Roberts et al., 2000 [40]; Djellal, 1995 [15]). Given the importance of knowledge for economic growth, KIBS can be considered as challenges to the traditional dichotomy between, the tangible, productive and progressive activities on the one hand, and the intangible and stagnant services on the other hand. Services have indeed often been regarded as low-productivity activities (Baumol, 1967 [4]) whose technical progress is dependent on manufacturing (Pavitt, 1984 [38]). 
The growth of KIBS in employment and wealth has boosted a certain number of empirical studies which emphasize a more productive and upgraded view of services. The analyses performed by Bessant and Rush (1995 [9]) and Hales (1997 [28]) focus on the role of consultants in "technology transfer", while expanding, to a certain extent, the semantic content of these two terms: "transfer" is not limited to its linear dimension, nor "technology" to its material dimension. In turn, Miles et al. (1995 [32]) provide an overview of the various activities performed by knowledge intensive business services and define these activities as users, diffusers and sources of innovation. On the macroeconomic level, using data from input/ output tables, Antonelli (1995 [2]) analyses the role of information and communication technology in improving the "connectivity" (the number of connections between agents in a network) and the "receptivity" of agents (their capacity to absorb information) through increased use of knowledge intensive business services. More recent works have taken a more indepth look at the role of KIBS in innovation in other activities and sectors (Muller and Zenker, 2001 [33]; Czarnitski and Spielkamp, 2003 [12]; Toivonen, 2004 [48]; Wood, 2005 [52]; OECD, 2007 [35]; Camacho abd Rodriguez, 2010 [10]; Tether and Hipp, 2002 [47]; Tomlinson, 2000 [49]; Rubalcabe and Kox, 2007 [44]; Hipp, 2008 [29]).

The different analyses and accounts previously mentioned can be unified and generalized in a model that can be linked to the Schumpeterian tradition. Gallouj (2002 [21]) has proposed to call this model "innovation model assisted by consultant", or more generally a model "of interactional innovation" or again "Schumpeter Mark 3" to show the connection to, and coherence with, the Schumpeterian approach. Gallouj believes that the model of interactional innovation extends the two Schumpeterian models (the Schumpeter Mark I entrepreneurial model (built on the symbolic figure of the individual entrepreneur) and the Schumpeter Mark II monopolistic model (in which the R\&D department replaces the entrepreneur)) in an interesting and unexpected way. It constitutes a new locus of expression of the Schumpeterian enterprise spirit: innovation can also come from interaction with external knowledge providers. Just as moving from the Schumpeter I model to the Schumpeter II model characterizes the historical evolution of capitalism, the appearance of the new model to some extent constitutes an additional stage in this evolution. This stage, that Schumpeter could not have anticipated, corresponds to the explosion of the tertiary economy, and in this general context, to the advent of a knowledge-based economy. 
Thus, mainly at the empirical level, a certain consensus seems to be established as regards the importance of KIBS for innovation and economic growth, This perspective for addressing innovation in services is labeled "inversion" (Gallouj, 2010 [23]). The inversion perspective reflects the "revenge" of the service sector. The argument is that of the existence of a certain inversion in the balance of power between the industrial sector and the services sector. The inversion perspective emphasizes the active role of KIBS in other sectors innovations. Nevertheless, theoretical models addressing the role of KIBS in economic growth are still quite rare and they provide a different appraisal of the role of KIBS. Baumol and Wolf (1983 [8]) and Baumol (2002 [5]) for example show that, because of highly labor intensive production processes, $R \& D$ activities are ultimately stagnant in the long run, casting doubt on the capacity of KIBS for sustaining the economic growth. Wolff (2002 [51]) also underlines that the growth of productivity in KIBS is particularly weak, even negative.

The aim of this paper is to confront and assess these contradictory approaches by building a theoretical model of economic growth which involves KIBS activities. We particularly seek to analyse the extent to which KIBS are an engine for economic growth, the mechanisms by which they can foster or, on the contrary, inhibit economic growth. Our purpose is also to know how KIBS can lead to a tertiarization process more autonomous vis-à-vis the industry. In the first section, we review and discuss the literature on the role of KIBS in long term growth. In the second section we build an agent-based model of economic growth and tertiarization, and finally, in the third section, we explore the emerging dynamics of the model in order to obtain answers to our research questions.

\footnotetext{
${ }^{1}$ The inversion perspective is a complement to the assimilation, differentiation and integration framework proposed by Gallouj (1994 [20] , Gallouj and Weinstein, 1997 [24]) in order to grasp the different theoretical perspectives used to address innovation in services in the literature. The assimilation (or technologist) perspective analyses innovation in services just as innovation in manufacturing, focusing on their relationships with technological systems. The differentiation (or demarcation or "service-oriented") perspective focuses on services specificities and aims to capture innovation activity where the traditional (technologist or assimilation) gaze perceives nothing. The integrative or synthetic perspective provides more a balanced view of innovation in services. It seeks to provide the same analytical frameworks for both goods and services, and for both technological and non-technological forms of innovation.
} 


\section{KIBS as an engine of economic growth and the sources of the growth of KIBS}

The purpose of the model we intend to propose is to shed a new light on the way KIBS can inpact on economic growth and on the general process of tertiarization. In order to formulate relevant hypotheses, we begin by confronting the different points of view encountered in the theoretical literature on economic growth and KIBS, then we discuss the drivers of such service demand by individual agents.

\subsection{KIBS and long term growth}

Few macroeconomic models have explored the role of KIBS in longterm economic growth. The studies performed by Baumol and Wolff are an exception to the rule.

Noting the weakness of the growth of productivity in KIBS sector these two authors (Baumol and al., 1994 [6]; Wolff, 2002 [51]), Baumol and Wolff (1983 [8]) and Baumol (2002 [5]) include R\&D services into the famous Baumol's unbalanced growth model (Baumol, 1967 [4]) in order to study the effects of a stagnation of labor productivity in $\mathrm{R} \& \mathrm{D}$ on the long-term growth of GDP. The model applied to R\&D and its conclusions can easily be generalized to all KIBS. Like many business services, R\&D has the specific characteristic of combining, on the one hand, "progressive" inputs, that is, inputs characterized by higher productivity gains than the average of the economy ${ }^{2}$ and, on the other hand, a "stagnant" input, that is, intellectual work. As Baumol (2002 [5]) has stated, "the act of thinking is a crucial input for the research process, but there seems to be little reason to believe that we have become more proficient at this handicraft activity than Newton, Leibnitz or Huygens" (p. 153). If we assume that there is an economy-wide single wage rate and that it increases at the average productivity rate, progressive input costs will decrease while the stagnant input one will increase. These opposed dynamics produce a non-monotonic R\&D cost trajectory: initially, the rapid drop in progressive input costs lowers total $\mathrm{R} \& \mathrm{D}$ costs, but it also gives rise to a progressive increase of the share of the stagnant input in the cost of this activity. Little by little, the cost disease that characterises the stagnant input impacts on the total cost of the R\&D service, which led Baumol and Wolff (1983 [8]) (see also Baumol, 2002 [5]) to de-

\footnotetext{
${ }^{2}$ This includes, for example, ICTs used by services firms and scientific and technical instruments used by researchers.
} 
scribe R\&D as an "asymptotically stagnant" service: over the long run, R\&D will become a too costly activity, threatening the continuity of the economic growth process in return.

This counter-intuitive viewpoint ${ }^{3}$ has been challenged by Oulton (2001 [36]). Oultons central argument is that Baumol and Wolff (1983 [8]) treated the demand for KIBS as a final demand, whereas it is intermediate by nature. According to Oulton, an industrial firm can choose between two types of substitutable inputs: labor and intermediate services (mainly KIBS). Due to their progressive input, KIBS benefit from a growth in productivity (even if it is a relatively weak growth) and they are necessarily less costly than the labor factor itself. Oulton concludes that demand for KIBS is therefore not likely to decrease over the long-term. Moreover, the increase in the share of these services in the overall employment generates a mechanical increase in productivity growth due to the addition of KIBS productivity growth to the one of manufacturing. Thus, contrary to Baumol and Wolff, Oulton concludes that KIBS growth should give rise to an acceleration of the economic growth rather than a deceleration.

Another argument in favour of the positive impact of KIBS on economic growth can be deduced from the results of the endogenous growth models. To generate a sustained growth in income per capita, these models incorporate a production factor which generates constant returns to scale into the framework proposed by Ramsey (1928), Cass (1965)and Koopmans $(1965)^{4}$. Two production factors are often highlighted in this context: human capital (Lucas, 1988 [31]) and knowledge (Romer, 1986 [42]). These factors allow an increase in the productive capacity of firms or individuals while generating positive externalities for other agents in the economy. This positive externality phenomenon certainly anables the endogenous and perpetual growth of labor productivity in the economy as a whole, but it also involves a distinction between the actual growth path of the economy and its optimal path. If we consider that the activity of a KIBS firm "consists of placing at the disposition of clients capabilities for processing information and knowledge" (Gallouj, 2002 [22] p.264), it can be said that KIBS bring together the two main factors of endogenous growth (human capital and knowledge). This observation strengthens the idea

\footnotetext{
${ }^{3}$ Growth theories generally see R\&D as an inexhaustible engine of long-term growth. This applies to evolutionary theories of economic change (Nelson and Winter, 1982 [34]; Barro and Sala-i-Martin, 2004 [3]) and endogenous growth theories (Romer, 1986 [42]; Lucas, 1988 [31]).

${ }^{4}$ For a detailed presentation of these models, see Barro and Sala-i-Martin (2004).
} 
that these services can be considered as a factor of perpetual growth of per capita income. However, endogenous growth models are not adapted to take into account the growth of the KIBS sector within the economy because they are based on the hypothesis of a single and perpetual growth engine, whereas KIBS are, in fact, an emerging engine. We need to be able to explain the reasons for this emergence and for the interactions between KIBS and the former growth engine, i.e. the accumulation of physical capital.

In his works on growth accounting, Abramovitz (1993 [1]) has already highlighted this growth engine transformation phenomenon. $\mathrm{He}$ states that "in the nineteenth century, technological progress was heavily biased in a physical capital-using direction [...] in the twentieth century, however, the physical capital-using bias weakened; it may have disappeared altogether. The bias shifted in an intangible (human and knowledge) capital-using direction" (p.224). We can therefore understand the phenomenon of the rapid growth of KIBS in employment as the most recent manifestation of a long process of replacing physical capital by human capital ${ }^{5}$. This finding limits the scope of Oultons model (2001 [36]) in explaining the process of KIBS growth in employment. Indeed, according to Oulton, this growth is the result of the replacement of the labor factor by KIBS, whereas it is rather the result of the replacement of one type of capital by another. If this hypothesis of the replacement of labor by KIBS is invalid, will the demand for KIBS ultimately be the victim of the cost disease as suggested by the Baumol and Wolff's model? In other words, is the demand for KIBS sensitive to price changes? These questions reveal the crucial link between the question of economic growth and the question of the factors driving the demand for KIBS.

\subsection{The motives for the demand for KIBS}

We have just underlined the necessity of understanding the factors driving the demand for KIBS. In this respect, Abramovitz (1993 [1]) is important, because he considers this demand as an investment rather than a consumption, whether final or intermediate. The advantage of such a conception is that an investment decision is not primarily determined by a price factor but by some strategic considerations, such

\footnotetext{
${ }^{5}$ This idea of replacing physical capital by human capital is included in the growth model put forward by Galor and Moav (2004 [26]; see also the Unified Growth Theory proposed by Galor, 2011 [25]), although it is not extended to the growth of the KIBS sector.
} 
as the necessity of remaining competitive. This can make the cost disease unlikely.

An argument in favor of this concept of KIBS as investment is provided by recent research on the capitalization of "intangibles". For Roth et al. (2010 [43]) these are "all capital forms that are of importance for productivity but are not included in the notion of physical capital". Faced with the incapacity of the traditional tools (mainly the neoclassical growth model and the usual growth accounting techniques) to explain the international differences in income per capita (Prescott, 1998 [39]) and the appearent contradiction between the data on productivity, wich exhibit a slow growth, and the observations of the pervasiveness of ICTs (the famous Solow paradox), a certain number of scholars (Corrado and al., 2009 [11]; Prescott, 1998 [39]; Roth and al., 2010 [43]) suggest to expand the concept of accumulative capital, previously limited to capital goods, to intangibles. Corrado and al (2009 [11]) distinguish three categories amongst the intangibles :

1. software acquisitions;

2. "innovative property", that is the expenditures of firms in "scientific" and "non-scientific" R\&D";

3. all the other spendings aiming to develop the "economic competencies" of the firm (design, advertising...).

All these categories include KIBS. According to Corrado et al (2009 [11]), all these intangibles are forms of investment because, by definition, they represent a "use of resources that reduces current consumption in order to increase it in the future" (p.666). This hypothesis is confirmed by Tether and Hipp (2002 [47]) who find, on the basis of a survey conducted within a panel of German service firms, that the primary source of competitivity for KIBS firms is the quality of the service provided, whereas the price appears to be amongst their less important sources of competitivity.

For Gallouj (2002 [22]), a KIBS firm can be described as a "knowledge accumulation system", which "accumulates, capitalizes and protects the knowledge derived from different service transactions". According to him, the demand for KIBS can be "explained less by transaction costs than by cognitive differentials" (p. 274). In other words, the quality of a KIBS provider is estimated by the client in terms of knowledge differentials. The more important the difference perceived by the potential clients is, the more the demand for KIBS will

\footnotetext{
${ }^{6}$ The field of services "non-scientific" $\mathrm{R} \& \mathrm{D}$ and especially " $R \mathscr{E} D$ in the social sciences and humanities" is addressed by Djellal and al. (2003 [16]).
} 
increase. For Baumol and al. (2007 [7] p.51), "unlike investment in a new machine, which has more or less predictable productivityenhancing consequences, investment in knowledge discovery is fraught with uncertainty". It can be said that a greater differential of knowledge reduces this uncertainty.

To conclude this section one can say that KIBS are likely to play a major and positive role in the generation of economic growth in the long run. First, KIBS can induce innovations amongst their clients. Second, despite a slow growth in their labor productivity, their demand is not heavily affected by the cost disease phenomenon. Nevertheless, the overall effect on economic growth remains unclear. First, the effect of KIBS on their clients'productivity, though positive, is less certain than the effect of acquisition of new capital goods. Second, following the hypothesis of the substitution for capital goods accumulation by intangibles accumulation, the growth of the sector of KIBS is followed by a de-growth in the sectors of machine tools. These contradictory dynamics and facts makes it necessary to build a model of economic growth in order to assess the overall effect of the emergence of KIBS on the economic growth in the long run.

\section{The model}

The analysis of the relationship between KIBS and growth has led us to introduce many feedbacks between different levels of aggregation. The economy appears then as a complex dynamic system, that is "an intricate system of interdependent feedback loops connecting micro behaviors, interaction patterns, and global regularities" (Tesfatsion, 2006 [46] p.833). There are two main techniques for modelling such systems: system dynamics modelling and the agent-based models (Scholl, 2001 [45]). In this paper, we choose the latter method, mainly because of its flexibility (Holland and Miller, 1991 [30]). There already exists a certain number of agent-based models of economic growth (see Dawid, 2006 [13] for a survey). Among them, the one proposed by Dosi and al. (2008 [19]; 2010 [27]; 2011 [17])is particularly interesting because it produces realistic emergent dynamics, and also because it is based on an explicit industrial growth engine. We begin this section by a presentation of this engine of growth, then we build our own model upon this baseline. 


\subsection{The vintage capital growth engine of Dosi et al}

The model proposed by Dosi et al. is a vintage capital model, i.e. it generates an economic growth thanks to the decisions of industrial firms to expand and regularly modernize their stock of machines. Let $i=1 \ldots n$ be the $n$ producers of capital goods and $j=1 \ldots m$ be the $m$ producers of consumer goods. Each of these latter possesses a stock of $k$ machines. The price rule of a firm $i$ at time $t$ is given by (1).

$$
p_{i t}=\left(1+\mu_{i}\right) \frac{w_{t}}{a_{i t}}
$$

$\mu_{i t}$ is a markup, $w_{t}$ is the level of wage at time $t$, which is indexed on the average level of productivity of the economy and $a_{i t}$ is the level of productivity of the firm $i$. The price rule of the firms $j$ is the same, except for $a_{j t}$ which is an average of the productivity of the $k$ machines possessed by $j$. The consumers are represented by a function of aggregate demand.

A firm $j$ can expand its capital stock by demanding new machines to $i$ in addition to its current machines, and it can also replace its obsolete machine-tools by more up-to-date ones. To do so, at each time step, $j$ reviews its machine-tools and decides to replace a machine $k$ if it satisfies the replacement criterion given by (2).

$$
\frac{p_{i t}}{\frac{w_{t}}{a_{k j t}}-\frac{w_{t}}{a_{i t}}}<b
$$

$b$ is a real and positive number, and $a_{k j t}$ is the level of productivity of the machine $k$ possessed by the firm $j$. Regularly, each producer of machine-tools $i$ tries to innovate. If an innovation is successful, it increases the productivity of the firm $a_{i t}$ and the one of the machine it provides. According to (1), the innovation will decrease the price $p_{i t}$ and increase the incentive of the firms $j$ for replacing their current machine-tools by the new one via the equation (2). The effect of this replacement investment will be a decrease of the price of the consumer goods provided by $j$, an increase in the overall productivity of the economy and of the level of wage. Consequently, consumers will be able to buy more goods, wich will give in return incentives to the consumer-goods firms $j$ to expand their stock of machine-tools and so on. Thus, a virtuous circle of endogenous economic growth is being set up by industrial firms. 


\subsection{A model of endogenous structural change}

We now expand the model proposed by Dosi et al. ${ }^{7}$ by adding to it $c=1 \ldots C$ individual consumers; $z=1 \ldots Z$ providers of consumerservices, a population of $g=1 \ldots G$ providers of KIBS, and a bank. The general functioning of the model during a time step is summed up in the figure 10. This figure includes our five types of agents while the bank implicitly appears with the "demand liquidities" action. Each one of the agents is associated with its main variables, denoted by $\mathrm{v}(0) ; \mathrm{v}(1) \ldots$. This allows to represent the if / then/ else structure of individual agents interactions. The order in which the figure should be read is summarized in table 3 and developed hereafter.

At the very begining of a time step, the computer mixes at random all the agents within each categories. Then, each agent computes its price, which will determine its level of competitivity compared to its competitors inside its sector of activity (capital goods, consumer services...). As in Dosi et al., each firm fixes its price level with the equation (1). The markup $\mu$ can be individualized, but we have chosen to give all the firms the same value ${ }^{8}$. For the firms $i$ and $g$, producing respectively capital goods and KIBS, the index of competitivity is given by (3), whereas it is given by (4) for the providers of consumer goods and services. The main rationale for the presence of the previous market shares $M S_{j t-1}$ in (4) is that consumers are heavily influenced

\footnotetext{
${ }^{7}$ It should be noted that we have not built our model upon the original code of the authors but only upon the principles given in Dosi and al. (2008 [19]; 2010 [27]; 2011 [17]). Our model has been written on the Laboratory for Simulation Development software, downloadable at: http : //www.labsimdev.org/Joomla 1 -3/

${ }^{8}$ In our simulations in this paper, $\mu=0.3$. The investments carried out by the firms of our different sectors are very different and then it can be relevant to differentiate the markups between sectors. However, we have chosen to give them all the same values for several reasons. First, even if the final good firms invest more heavily than capital goods firms, we need to reward the innovative effort of the machine suppliers. Second, it would have been possible to differentiate the markups even inside the sectors and let the market selects the emergent markup for each sector. However if this process is probably a good way to fix the markup, it can produce a lot of different dynamics, and therefore the results of the simulations would be difficult to compare between each other.

The price decided by the consumer-goods firms cannot include the capital costs, because if we do so, no consumer would have enough money for buying something. So, the profit of these firms can easily be negative. But, as we will see, in our model the firms only invest in capital goods when they have enough liquidities. That means that they have negative profits in a first step, when they have liquidities and when they grow. But, after a certain number of time steps, firms make the experience of alternate periods of negative and positive profits: they invest and have negative profits after the periods of no investment and positive profits.
} 
by social pressure in their consumption choices (see [41]; [50] and [37]).

$$
\begin{gathered}
\text { Competitivity }_{i t}=\left(\frac{a_{i t}}{p_{i t}}\right)^{\zeta 1} \\
\text { Competitivity }_{j t}=\left(\frac{M S_{j t-1}}{p_{j t}}\right)^{\zeta 2}
\end{gathered}
$$

The level of wage is equal the average labor productivity within the economy ${ }^{9}, w_{t}=\bar{A}_{t}$.

KIBS firms have already their production capacity established by their employees. The general rule in our model is that firms employ a worker/consumer only for one time step; but in the case of KIBS firms, workers are employed for a longer period since these firms regularly invest in the training of their current staff. This point will be developed thereafter.

\subsubsection{The industrial firms (consumer-goods firms and capital-goods firms)}

Consumer-good firms $j$ begin by formulating their demand expectation for the current time step $D_{j t}^{e}$ following the adaptive behavior decribed by the equation ${ }^{10}(5)$.

$$
D_{j t}^{e}=D_{j t-1}^{e}+\beta\left[D_{j t-1}-D_{j t-1}^{e}\right]
$$

$D_{j t-1}$ represents the quantities actually required in the previous period and $\beta \epsilon[0 ; 1]$. More this parameter is approaching its upper value, more the firm will react rapidly to its errors of expectations, and then, more the volatility of the aggregate production will be important. On the contrary, more $\beta$ approaches 0 , stronger will be the inertia in the behavior of the firm. Comparing $D_{j t}^{e}$ with the level of

\footnotetext{
${ }^{9}$ This hypothesis is not detrimental to the capitalists of this artificial economy. Indeed, first as we will see loans are paid by an interest rate, which constitutes an income for the capitalists, and second there is the presence of the markup coefficient $\mu$ in the pricing rule applied by firms, which is also a source of income for the capitalists. Moreover, this hypothesis is the simplest we can formulate in order to be coherent with Baumol's essential hypothesis as regards wage (Baumol, 1967 [4]). Indeed, for obtaining the cost disease, "wages in the two sectors of the economy [have to] go up and down together" (p.417).

${ }^{10}$ Dosi and al. (2006 [18]) tests a wide variety of routines for the demand expectations of their firms (myopic expectations, autoregressive expectations, accelerative expectations, adaptive expectations, micro-macro expectations). They found that this choice mainly influences the volatility of the macroeconomic variables, such as GDP and investment.
} 
its inventories $S_{j t}$ inherited from the previous time steps, the firm $j$ decides whether it will be necessary or not to demand a number of work hours $L_{j t}^{d}$, as in the following algorithm.

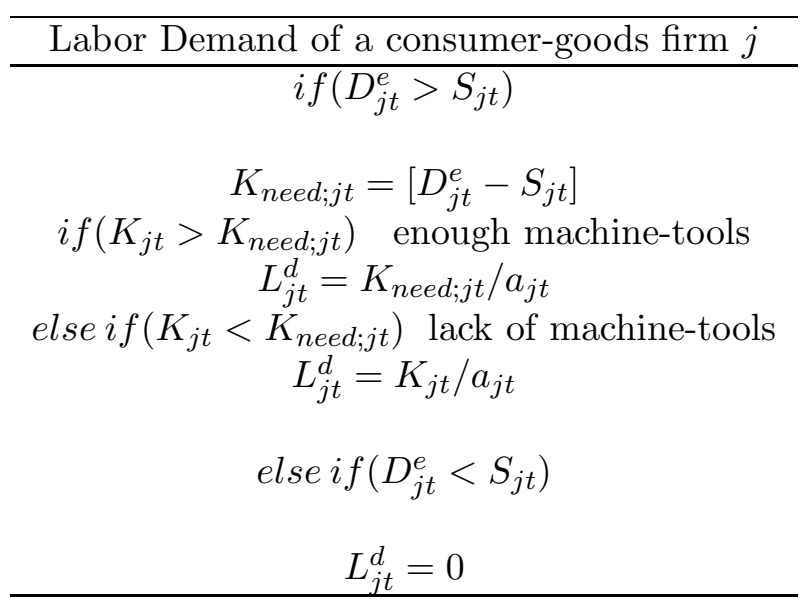

$K_{\text {need; } j t}$ is the number of capital goods needed by the firm $j$ for producing the desired quantity $\left(D_{j t}^{e}-S_{j t}\right)$. Then, $L_{j t}^{d}$ will depend on the amount of machine-tools $K_{j t}$ actually possessed by $j$. If $K_{j t}$ is not sufficient, the firm will try to expand its capital stock through a capacity investment.

Afterwards, the firm $j$ reviews its machine-tools and tries to replace the ones which are obsolete according to the procedure described in Dosi et al. (see equation 2). We have marginally modified this procedure in two points : (1) in our model, the firm only reviews a percentage $\Theta$ of its machine-tools, (2) the firm demands a new machine only if it has enough liquidities. If not, it can try to borrow at the bank.

Let $L_{j t}^{o}$ be the number of work hours really obtained by $j$ in the labor market, the quantity $y_{j t}$ of consumer-goods produced and added to its inventories is given by $(6)$.

$$
y_{j t}=a_{j t} \times L_{j t}^{o}
$$

When all the consumer goods firms have demanded for machine tools, each supplier $i$ of capital goods requires the necessary number of work hours given by (7).

$$
L_{i t}^{d}=D_{i t} / a_{i t}
$$

$D_{i t}$ is the total number of machine tools actually demanded to $i$ 
by its clients. With $L_{i t}^{o}$ the number of work hours really obtained and $a_{i t}$ the labor productivity of the capital goods supplier, its production $y_{i t}$ is given by (8).

$$
y_{i t}=a_{i t} \times L_{i t}^{o}
$$

The produced machine tools will be delivered at the end of the time step. Thus, the new machines will only be available for the clients $j$ starting from the next period. The payment is only done at that time by the clients in order to avoid a situation where machines have been paid but without being delivered because of an insufficient production of capital goods due to a labor shortage on the labor market. At each time step, a share $\gamma$ of the sales, $p_{i t} \times y_{i t}$, is invested by $i$ in $R \& D$. Noting $\eta$, a scale parameter and $U(0 ; 1)$ a random draw in a Uniform law of probability, an innovation occurs if the condition (9) is fulfilled.

$$
U(0 ; 1)<1-e^{-\eta \times p_{i t} \times y_{i t}}
$$

The innovation can introduce a better technology than the one available or not. So, when condition (9) is verified, another random draw in $U(-0.5 ; 0.5)$ is realized. If the outcome of this latter is positive, the labor productivity of $i$ and of the machine tools it sales are incremented by this second random draw. In the opposite, if the outcome of this second random draw is negative, then the new technology is not adopted and the productivity of the firm $i$ and of the machine it sales are not modified. This process will give incentives to consumergoods firms to replace their existing capital goods in the next time step according to (2).

\subsubsection{Consumer-service firms}

We modelize a pure service sector where there is no need for capital goods for producing. Thus, the $Z$ consumer-service firms are totally stagnant in an economy where the technical progress comes only from the industrial sectors. The typical firm $z$ begins by formulating its demand expectation (10), as its industrial counterparts. By analogy, we note $D_{z t}^{e}$ this expectation for the current time step and $D_{z t-1}$ the quantities of services actually demanded in the previous period.

$$
D_{z t}^{e}=D_{z t-1}^{e}+\beta\left[D_{z t-1}-D_{z t-1}^{e}\right]
$$

Because a service is non-storable, the labor demand $L_{z t}^{d}$ is directly given by (11).

$$
L_{z t}^{d}=D_{z t}^{e} / a_{z t}
$$


$a_{z t}$ is the labor productivity within the firm $z$. Noting $L_{z t}^{o}$ the number of work hours really obtained by $z$ in the labor market, the production capacity is expressed by (12).

$$
y_{z t}=a_{z t} \times L_{z t}^{o}
$$

\subsubsection{Final consumers}

Now, all the consumers/ workers $c$ who are still unemployed will not find a job any more during the remaining of the time step. The budget $B_{c t}$ of an agent $c$ who has been employed in $t$ is given by (13), in the other case $B_{c t}$ is only equal to the sum of the unconsumed budgets inherited by the agent $c$ from the previous periods, $B_{c t-1}$.

$$
B_{c t}=B_{c t-1}+w_{t}
$$

An Engel's law is implemented in the form of a variable $\vartheta_{t}$ which determines the share of his budget a consumer will devote to the consumption of services. Denoting $\vartheta_{\min }$ and $\vartheta_{\max }$ respectively the minimum and the maximum value of this share, and $\iota$ a scale parameter, $\vartheta_{t}$ is given by (14).

$$
\vartheta_{t}=\vartheta_{\min }+\frac{\vartheta_{\max }-\vartheta_{\min }}{1+e^{-\iota \times w_{t}}}
$$

Afterwards, each consumer $c$ chooses a supplier of consumer-goods and a supplier of consumer-services. The supplier selection procedure used is a random selection in which each firm in the same class has a chance proportional to its competitiveness index ${ }^{11}$ to be chosen by $c$. Each consumer tries to consume his whole budget.

\subsubsection{KIBS firms}

By now, all the operations of buying and selling goods, services and capital goods have been done. If a firm has made positive profits, it can try to invest in knowledge by calling on the services of a KIBS firm. To achieve this goal, the profitable firm chooses randomly a KIBS supplier and compares its own level of knowledge, $H_{\text {client }, t}$, with that of the chosen KIBS firm, $H_{K I B S, t}$. If the company finds a cognitive gap, it makes an investment in knowledge. The result of a random draw in a uniform distribution, $U\left(H_{\text {client }, t} ; H_{K I B S, t}\right)$, will be added to

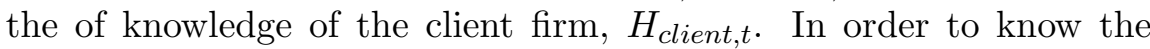
result in terms of innovation for the client firm, another random draw in a uniform distribution, $U(-\kappa ; \kappa)$, is performed, with $\kappa$ a parameter

\footnotetext{
${ }^{11}$ Computed like in the equation (4)
} 
that gives the potential impact of a growing level of knowledge on the productivity of the client firm. If the result of $U(-\kappa ; \kappa)$ is positive, then it is added to this labor productivity.

Behind this mechanism lies the idea that KIBS firms are a vehicle for the diffusion of knowledge in the economy, and that there is a link, which is certainly not automatic, between knowledge and innovation. All the sectors of the economy, even the traditionally stagnant services, can demand knowledge to KIBS firms and benefit from innovations (Roberts et al. 2000 [40]). In this respect, we differentiate the $\kappa$ parameter in order to distinguish between industrial and service clients and to reproduce different scenarios, particularly the cost disease one when $\kappa_{\text {Services }}<\kappa$, with $\kappa_{\text {Services }}$, the impact parameter for service firms. It should also be underlined that the induction of an increase of productivity within the client firms can foster the process of substitution of knowledge accumulation for capital accumulation for explaining the economic growth. Indeed, if the labor productivity of the consumer-goods firms is increased, then the condition (2) will be less and less easily fulfilled, reducing capital investment for productivity reasons. But in the same time, machine suppliers can also invest in KIBS and benefit from an increase of productivity, encouraging in reverse the consumer good firms to replace their existing capital goods by the new ones, more productive. The difficulty to predict the final outcome of these conflicting incentives reveals the interest of building growth models incorporating KIBS.

To remain competitive, KIBS companies are engaged in a race for the accumulation of knowledge. They can increase their knowledge in two ways. The first one is automatic and unexpensive. It consists of learning by doing. In this case, the level of knowledge of the KIBS firm is increased by the result of a random draw in a uniform distribution $\mathrm{U}(0,0.25)$. The second way is deliberate and costly. For a KIBS firm a market share below the average is the sign of a cognitive gap. In this case, it compares its own level of knowledge with the maximum level during the previous time step. We note $\left(H_{\max , t-1}-H\right)$ this differential and $e^{\left(H_{\max , t-1}-H\right)}$ the cost of employee training necessary for totally reducing this differential. If firm's liquidities are sufficient, the investment in training is done and its new level of knowledge becomes $H_{\max , t-1}$.

Because of these investments in staff training, we assume that the employment in KIBS firms is not as flexible as the one in the other sectors of the economy. Thus, a KIBS firm will decide to employ 
a new worker only when the demand for its services are sufficiently higher than its production capacities, and conversely, it will decide to dismiss an employee only when the demand is sufficiently lower than its production capacities.

\subsubsection{Banking system and entry-exit rules}

Each agent of the model (firms and consumers) has a current account at the bank. This account yields no interest, but all agent can use all its cash as it sees fit. The bank is unique. This ensures it will never bankrupt: when an agent withdraws its cash, it is necessarily for paying another agent, which will deposit its cash in the same bank. Firms can apply for loan in two situations: (1) consumer goods firms may seek to finance investment in capital goods, (2) all firms may request a loan when their liquidities become negative. In this case, the bank observes their solvency by calculating the ratio (Debt/Sales) of the applicant. If $($ Debt/Sales $)<k$, with $k=2$ in the simulations presented here, then the bank grants an extension of cash of the amount $(k \times$ sales $)-$ debts. This loan is to be repaid in $A$ time steps at the periodic interest rate $r$, with $A=10$ and $r=5 \%$ in this paper. A new loan may be contracted by the client firm to repay an old debt if Debts/Sales $<k$. In case of bankruptcy of the client firm, the bank cannot fail since its financial capacity is equivalent to nominal GDP.

This financial system lowers the rate of entries and exits of firms in the model. The general rule for entries and exits is the following : when a firm has a negative amount of liquidities, it is removed from the model, and immediatly replaced by a new one, which is a copy of one of the surviving firms ${ }^{12}$. In the case of the consumer-goods firms, the stock of capital goods of the new entrant is equal to the average level of capital stock necessary for the existing firms during the current time step. In the case of the KIBS firms, the level of knowledge of the new entrant is equal to the maximum level of knowledge among the KIBS firms at the previous time step.

\footnotetext{
${ }^{12}$ Regardless the proportion between exiting firms and surviving firms, the new entrants are a copy of a surviving one. This copied surviving firm is selected randomly, with a probability of being chosen proportional to the amount of its liquidities. The implicit assumption behind this mechanism is that the new entrant copies the most successfull firms. Moreover, there is always at least one firm which can be copied because the firm's exit is computed sequentially : all the firms cannot exit the market at the same time. Even in a theoretical case where all the firms have to exit during the same time step, the firms exit one after another during this time step.
} 


\begin{tabular}{|c|c|c|}
\hline & TestStat & P-value \\
\hline Dickey-Fuller & -6.53403 & $1.55321 \mathrm{D}-07$ \\
\hline Phillips-Perron & -303.84520 & $6.95894 \mathrm{D}-31$ \\
\hline
\end{tabular}

Table 1: Unit root tests for the GDP growth rate

\section{Simulation Results}

The literature review on the long term impact of KIBS on economic growth has revealed the complexity of the question : in order to provide an answer, it is necessary to include multiple and contradictory relations between agents behaviors and macro dynamics. This complexity led us to build the agent-based model presented in the previous section. Now, we explore the macro and meso-dynamics it generates, but, before exploiting these results, we need to ensure that they are relevant in both statistic and economic terms.

\subsection{Model significance}

The figures presented in this paper come from an average of 50 simulation runs, each one computed with a different random seed. The table 2 gives the initial conditions and the values of the parameters used for running the simulations. The reference scenario that we analyze in this section has the following parameter values: $\Theta=0.5$, the share of their capital goods that each consumer-goods firm compares with the newest machines on the market at each time step; $\kappa=0.5$ and $\kappa_{\text {Services }}=0.25$, which are the parameters of maximum impact of KIBS, respectively on the productivity of their industrial and of their tertiary clients. These differences of values between $\kappa$ and $\kappa_{\text {Services }}$ are justified by the fact that we consider the situation of laggard consumer services as a relevant situation.

In terms of statistical relevance, we have applied a Dickey-Fuller and a Phillips-Perron test on the rate of growth of the obtained average GDP (table 1). None of them permits to conclude that there is a unit root in our time series. Besides, the figure 1, which shows the logarithm of the generated GDP, reveals a rather constant confidence interval over time, wich confirms that there is no explosive tendency. The overall stability of our agent-based system is also confirmed by the evolution of the unemployment rate (figure 2) which fluctuates asymptotically around $2.5 \%$ with a stable confidence interval.

From an economic point of view, we observe that the level of GDP becomes temporarily stagnant, or even decreases, approxima- 
Figure 1: Logarithm of GDP in the reference scenario

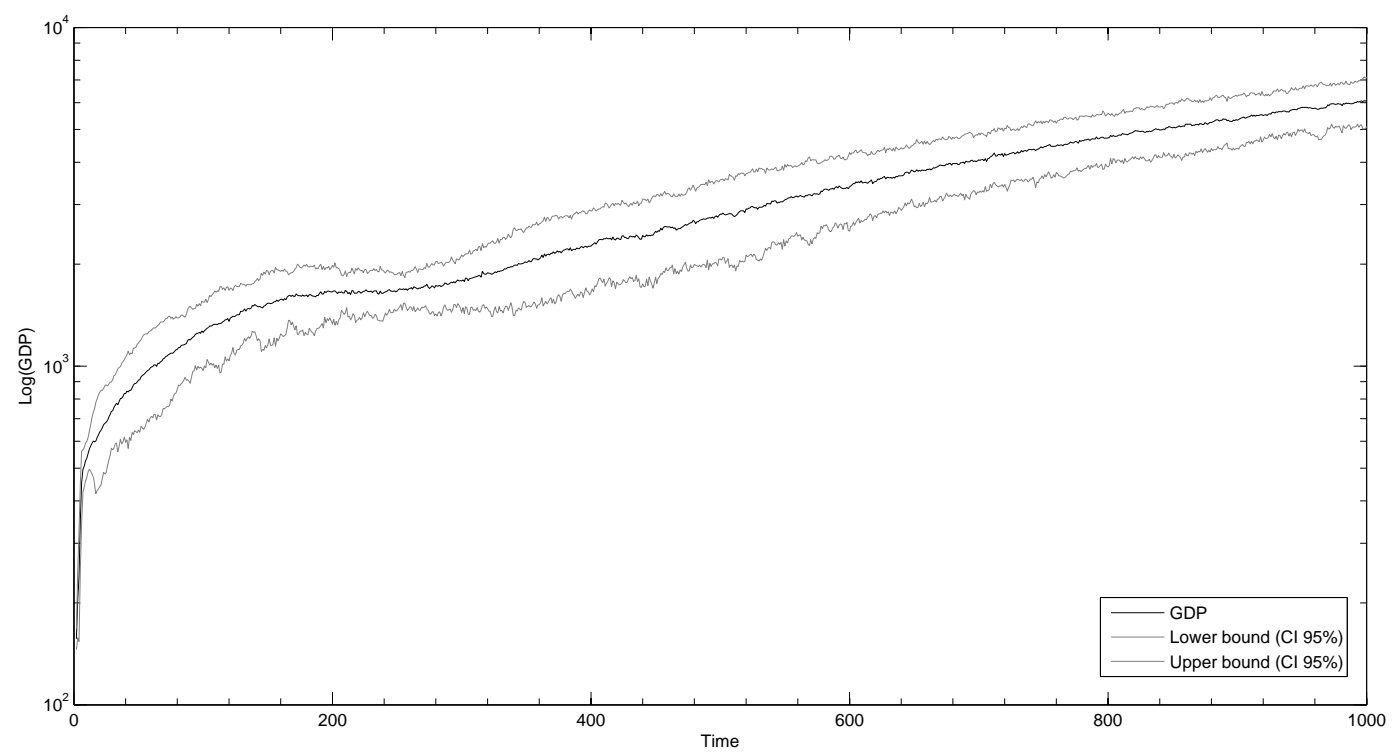

Figure 2: Unemployment rate

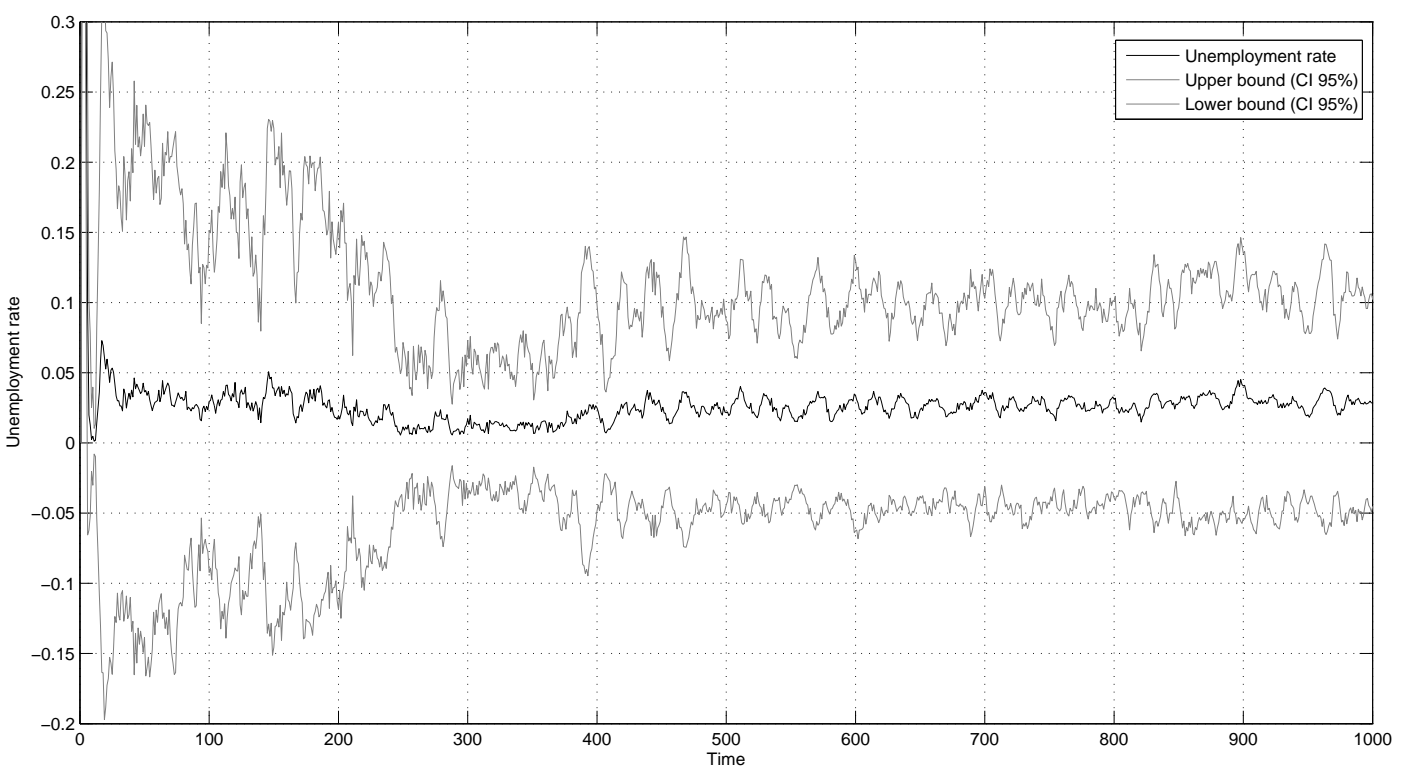

tively when $t \in[200 ; 300]$. The figure 3 reveals in its part (a) that this time span corresponds to a period where an important tertiarisation 
process takes place in the model: the employment shifts from the productive industrial sectors to the unproductive consumer services. At that time, KIBS services are rapidly growing but they are not sufficiently important in the employment for enough counterbalancing the effect of this structural change on the economic growth. It is the kind of situation predicted by the Baumol's unbalanced growth model ([4]). The Figure 4 reveals indeed that the labor productivity in consumer services only begins to grow when $t \in[200 ; 300]$, this increase is only due to the growing importance of KIBS.

In the construction of the model, we have underlined the unpredictable outcome of the contradictory incentives, coming from investments in KIBS, for the accumulation of capital goods. On this respect, the occuring shift in employment at the advantage of KIBS compared with providers of machine tools reveals clearly that the negative incentives outweigh. We can compare the differences between the sectoral employment dynamics on the figure 3 (a), where $\Theta=0.5$, with the ones illustrated by the figure $3(\mathrm{~b})$, where $\Theta=0.1$. In this latter case, the employment in KIBS sector immediately reaches its long run level: consumer good firms are too few sensible to an increase in the productivity of the machines provided by the capital good sector, so that their investment in KIBS gives them strong incentives for rapidly substituting intangibles for physical capital accumulation.The crucial role of $\Theta$ on the rate of growth of the KIBS sector in the employment reveals that, in our model, the tertiarisation process is heavily dependent on the industry.

During the following periods $(t>300)$, the GDP enters a stable growth path. The figure 4 shows that, during this period, there is a break in the trend of productivity growth in the industrial sectors and a stable growth of productivity within the (previously stagnant) consumer service sector. This break is explained by the substitution of intangibles for capital goods accumulation. In order to explain this point, figure 5 decomposes the relationship between physical capital investment and level of GDP in two subperiods : when $t<250$ and when $t>250$. We observe that, in the first subperiod, the relationship is clearly positive and linear. The dynamics described in the second subperiod are more complex. We observe two clouds of points : one on the bottom-right side and another on the upper-left side of the part (b) of the figure. The first cloud is linked to the second one by a transition period where an increase of GDP takes place despite a decrease in material investment. This period corresponds to $t \in[250 ; 400]$, when KIBS begin to outweigh the sector of capital goods in employment. 
After this transition phase, there is no clear relationship between material investment and GDP, whereas the figure 6 reveals that there is, for the concerned level of GDP $(G D P>2500)$, a linear and positive relationship between the economic growth and the level of knowledge. Because of the link between knowledge and innovation in our model, we can say that when $t>400$ the economic growth is mainly explained by the accumulation of intangibles. This confirms Abramovitz (1993 $[1])^{13}$ and Corrado et al.'s analyses [11] of the growing importance of intangibles for economic growth.

Our main objective in this subsection was to assess the relevance of the aggregated dynamics produced by our agent-based system. We found that they are robust in statistical terms and also that the system is able to generate a coherent time path of GDP and an entire tertiarisation process. Moreover, we observe a major qualitative change with the substitution of the intangibles accumulation for the capital goods accumulation. We can say that KIBS are after all a positive factor of economic growth because we found that the tertiarisation process, without an important KIBS sector, produces a stagnation of GDP. This subsection has also revealed the important role of the replacement of the existing capital goods in order to explain the speed of the growth of the KIBS sector : the more important this investment is, the slower the the emergence of KIBS is. The tertiarisation process appears then as dependent on the industry, but, because of the impact of KIBS investment on the productivity of the client firms, we want to know if, despite a first period of dependence, the growth of KIBS, and ultimately the tertiarisation process in itself, cannot become self-sustained.

\subsection{KIBS and the autonomy of the tertiarisa- tion process}

In order to answer the question of the autonomy of the process of tertiarisation, and also in order to identify the channels by which KIBS can impact on economic growth, we analyse the effect of different values of the $\kappa$ and $\kappa_{\text {Services }}$ parameters on the level of GDP and on the level of the share of services in employment. We recall that $\kappa$ and $\kappa_{\text {Services }}$ are respectively the parameters of maximum impact of KIBS on the productivity of their industrial and of their tertiary clients. We have tested all the possible combinations of these two parameters for $\kappa \in[0.1 ; 0.5]$ and $\kappa_{\text {Services }} \in[0.1 ; 0.5]$. The time steps considered

\footnotetext{
${ }^{13}$ See the citation of Abramovitz in our section 2.1 .
} 
are: $t=100$, because at that time, the economy of the model is mainly an industrial economy; $t=250$ because we have seen that the tertiarisation process takes place at that time; and $t=1000$ when the economy is a service economy. The results are reported on the figure 7.

\subsubsection{Results for $\mathrm{t}=100$}

These results are reported on the parts (a) and (b) of the figure 7 . At first, we observe a clear positive impact of an increase of $\kappa$ on the level of GDP. But in the same time, for any level of $\kappa$, none of the levels of $\kappa_{\text {Services }}$ seems to affect the level of the GDP. Consequently, we can say that KIBS are already a factor of economic growth during the industrial phase of the economy, but only via their impact on the industrial firms. Concerning their influence upon the general tertiarisation process, the part (b) of the figure suggests that it is only via the industrial firms that KIBS can induce an increase in share of services in the employment.

\subsubsection{Results for $\mathrm{t}=\mathbf{2 5 0}$}

At that time (figure 8), the employment is rapidly shifting from industrial to tertiary sectors. We still notice a strong positive relationship between $\kappa$ and the level of GDP, but we also begin to observe a positive impact of an increase in $\kappa_{\text {Services }}$ when $\kappa$ is itself at its higher level. The part (b) of the figure suggests that these specific combinations of $\kappa$ and $\kappa_{\text {Services }}$ correspond to a share of services in the overall employment approximatively equal to $60 \%$. As far as the tertiarisation process is concerned, we can say that $\kappa_{\text {Services }}$ has still no influence, no matter the value of $\kappa$.

\subsubsection{Results for $\mathrm{t}=\mathbf{1 0 0 0}$}

In this case, the tertiarisation process is over (figure 9). Indeed near $80 \%$ of jobs are in services for a wide range of combinations of $\kappa$ and $\kappa_{\text {Services. }}$. Because of this prevalence of the service activities, the impact on the GDP of an increase of $\kappa_{\text {Services }}$ appears to be stronger than the impact of an increase in $\kappa$, revealing that the economic growth is now primarily based on the service sectors. We remark also that an increase of $\kappa$ continues to generate a higher level of GDP, even if we are in a tertiary economy.

This section has provided additional evidence on the positive role of KIBS on economic growth. As the tertiarisation process goes on, 
the channel through which KIBS act on GDP moves from industry to services. We can also say that, in a certain way, KIBS impact on the tertiarisation process because they exacerbate the productivity differentials between industry and services, but not because they produce an increment of labor productivity within service sectors. The tertiarisation process appears then always dependent on the industry, despite the increasing importance of KIBS.

\section{Conclusion}

Despite a strong link between KIBS, knowledge and innovation, the question of the impact of KIBS on the process of economic growth is difficult to address, because the ultimate effect of KIBS depends on the motivations of the demand for KIBS. If this demand is a form of consumption, the cost disease can inhibit the economic growth, but if it is a form of investment, the demand for KIBS is less affected by a high inflation rate in these activities. Moreover, we have seen that an increase of KIBS share in production and employment can induce a degrowth in the capital goods sector, which is traditionally at the source of the productivity gains within the modern economies. Because of these numerous contradictory consequences of the emergence of KIBS for economic growth, we have built a multi-agent system which is able to generate an economic growth and a tertiarisation process. The simulations we have conducted reveal, for a wide range of parameters, that KIBS are ultimately a factor of economic growth. As in the recent works on intangibles (Roth et al., 2010 [43]; Corrado et al., 2009 [11]), we have established that, during the process of economic growth, the source of the increasing labor productivity has shift from industry to services, even if the driving force of the tertiarisation process remains the industrial sectors. We remark also that the industry always appears as a significant factor for explaining the economic growth, even if it is via the demand of industrial firms for KIBS.

\section{References}

[1] Moses Abramovitz. The search for the sources of growth: areas of ignorance, old and new. The Journal of Economic History, 53(2):217-243, 1993.

[2] Cristiano Antonelli. The Economics of Localized Technological Change and Industrial Dynamics. Kluwer Academic Publishers, 1995. 
[3] Robert J. Barro and Xavier Sala i Martin. Economic Growth. The MIT Press, 2004.

[4] William J. Baumol. Macroeconomics of unbalanced growth: the anatomy of urban crisis. The American Economic Review, 57:415-426, 1967.

[5] William J. Baumol. Services as leaders and the leader of the services. In Jean Gadrey and Faïz Gallouj, editors, Productivity, Innovation and Knowledge in Services, chapter 7, pages 147-163. Edward Elgar, 2002.

[6] William J. Baumol, Sue Anne Batey Blackman, and Edward N. Wolf. Productivity and American leadership: the long view. The MIT PRess, 1994.

[7] William J. Baumol, Robert E. Litan, and Carl J. Schramm. Good Capitalism, Bad Capitalism, and the Economics of Growth and Prosperity. Yale University Press, 2007.

[8] William J. Baumol and Edward N. Wolf. Feedback from productivity growth to r\&d. The Scandinavian Journal of Economics, 85:147-157, 1983.

[9] John Bessant and Howard Rush. Building bridges for innovation: the role of consultants in technology transfer. Research Policy, 24(1):97-114, 1995.

[10] José A. Camacho and Mercedes Rodriguez. How important are knowledge-intensive services for their client industries? an assessment of their impact on productivity and innovation. In Faïz Gallouj and Faridah Djellal, editors, The Handbook of Innovation and Services. A Multi-Disciplinary Perspective, chapter 18, pages 424-447. Edward Elgar, 2010.

[11] Carol Corrado, Charles Hulten, and Daniel Sichel. Intangible capital and u.s. economic growth. The Review of Income and Wealth, 55(3):661-685, 2009.

[12] Dirk Czarnitzki and Alfred Spielkamp. Business services in germany: bridges for innovation. The Service Industries Journal, $23(2): 1-30,2003$.

[13] Herbert Dawid. Agent-based models of innovation and technological change. In Leigh Tesfatsion and Kenneth L. Judd, editors, Handbook of Computational Economics. Agent-Based Computational Economics, chapter 25, pages 1235-1272. North-Holland, 2006.

[14] Pim den Hertog. Knowledge-intensive business services as coproducers of innovation. International Journal of Innovation Management, 4(4):491-528, 2000. 
[15] Faridah Djellal. Changement technique et conseil en technologie de l'information. L'harmattan, 1995.

[16] Faridah Djellal, Dominique Francoz, Camal Gallouj, and Faïz Gallouj. R\&d in services. revisiting the definition of research and development in the light of the specificities of services. Science and Public Policy, 30:415-429, 2003.

[17] Giovanni Dosi, Giorgio Fagiolo, Mauro Napoletano, Andrea Roventini, and Tania Treibich. Heterogeneous banks and technical change in an evolutionary model of endogeneous growth and fluctuations. Working Paper, january 2011.

[18] Giovanni Dosi, Giorgio Fagiolo, and Andrea Roventini. An evolutionary model of endogenous business cycles. Computational Economics, 27:3-34, 2006.

[19] Giovanni Dosi, Giorgio Fagiolo, and Andrea Roventini. The microfoundations of business cycles: an evolutionary, multi-agent model. Journal of Evolutionary Economics, 18:413-432, 2008.

[20] Faïz Gallouj. Economie de l'innovation dans les services. L'Harmattan, 1994.

[21] Faïz Gallouj. Interactional innovation: a neoschumpeterian model. In Sundbo J. and Fuglsang L., editors, Innovation as strategic reflexivity. Routledge, 2002.

[22] Faïz Gallouj. Knowledge-intensive business services: processing knowledge and producing innovation. In Jean Gadrey and Faïz Gallouj, editors, Productivity' innovation and knowledge in services, chapter 11, pages 256-284. Edward Elgar, 2002.

[23] Faïz Gallouj and Faridah Djellal. Introduction: filling the innovation gap in the service economy - a multidisciplinary perspective. In Faïz Gallouj and Faridah Djellal, editors, The Handbook of Innovation and Services. A Multi-disciplinary Perspective, chapter Introduction, pages 1-23. Edward Elgar, 2010.

[24] Faïz Gallouj and Olivier Weinstein. Innovation in services. Research Policy, 26:537-556, 1997.

[25] Oded Galor. Unified Growth Theory. Princeton University Press, 2011.

[26] Oded Galor and Omer Moav. From physical to human capital accumulation: inequality and the process of development. Review of Economic Studies, 71:1001-1026, 2004.

[27] Giorgio Fagiolo Giovanni Dosi and Andrea Roventini. Schumpeter meeting keynes: a policy-friendly model of endogenous 
growth and business cycles. Journal of Economics Dynamics and Control, 34:1748-1767, 2010.

[28] Mike Hales. Make or buy in the production of innnovation. Report for The European Commission (TSER Programm, DGXIII), 1997.

[29] Christiane Hipp. Service peculiarities and the specific role of technology in service innovation management. International Journal of Services Technology and Management, 9(2):154-173, 2008.

[30] John H. Holland and John H. Miller. Artificial adaptive agents in economic theory. The American Economic Review, 81(2):365370, 1991.

[31] Robert E. Lucas. On the mechanics of economic development. Journal of Monetary Economics, 22:3-42, 1988.

[32] Ian Miles, Nikos Kastrinos, Kieron Flanagan, Rob Bilderbeek, Pim den Hertog, Willem Huntink, and Mark Bouman. Knowledge-intensive business series. users, carriers and sources of innovation, march 1995.

[33] Emmanuel Muller and Andrea Zenker. Business services as actors of knowledge transformation: the role of kibs in regional and national innovation systems. Research Policy, 30(9):1501-1516, 2001.

[34] Richard R. Nelson and Sidney G. Winter. An Evolutionary Theory of Economic Change. Harvard University Press, 1982.

[35] OECD. Summary Report of the Study of Globalisation and Innovation in the Business Services Sector. OECD, 2007.

[36] Nicholas Oulton. Must the growth rate decline? Oxford Economic Papers, 53(4):605-627, 2001.

[37] Vance Packard. The waste makers. Penguin Books, 1960.

[38] Keith Pavitt. Sectoral patterns of technical change: towards a taxonomy and a theory. research Policy, 13:343-373, 1984.

[39] Edward C. Prescott. Needed: a theory of total factor productivity. International Economic Review, 39(3):525-551, 1998.

[40] Joanne Roberts, Ian Miles, Richard Hull, Jeremy Howells, and Brigite Andersen. Introducing the new service economy. In Brigite Andersen, Jeremy Howells, Richard Hull, Ian Miles, and Joanne Roberts, editors, Knowledge and Innovation in the New Service Economy, chapter 1, pages 1-6. Edward Elgar, 2000.

[41] Everett M. Rogers. Diffusion of innovations. The Free Press, 1995. 
[42] Paul M. Romer. Increasin returns and long-run growth. Journal of Political Economy, 94:1002-1037, 1986.

[43] Felix Roth, Anna Thum, and Mary O'Mahony. Intangible capital and productivity growth: a literature review with a special focus on the service industry. Working Paper, December 2010.

[44] Luis Rubalcaba and Henk Kox. Business Services in European Economic Growth. Palgrave-MacMillan, 2007.

[45] Hans Jochen Scholl. Agent-based and system dynamics modeling: a call for cross study and joint research. In Proceedings of the 34th Annual Hawaï International Conference on System Sciences, 2001.

[46] Leigh Tesfatsion. Agent-based computional economics: a constructive approach to economic theory. In Leigh Tesfatsion and Kenneth L. Judd, editors, Handbook of Computational Economics, volume 2, chapter 16, pages 831-880. North-Holland, 2006.

[47] Bruce S. Tether and Christiane Hipp. Knowledge intensive, technical and other services: patterns of competitiveness and innovation compared. Technology Analysis and Strategic Management, 14(2):163-182, 2002.

[48] Marja Toivonen. Expertise as business: Long-term development and future prospects of knowledge-intensive business services. PhD Thesis, 2004.

[49] Mark Tomlinson. The contribution of knowledge-intensive services to the manufacturing industry. In Brigite Andersen, Jeremy Howells, Richard Hull, Ian Miles, and Joanne Roberts, editors, Knowledge and Innovation in the New Service Economy, chapter 3. Edward Elgar, 2000.

[50] Ulrich Witt. Learning to consume-a theory of wants and the growth of demand. Journal of Evolutionary Economics, 11:23$36,2001$.

[51] Edward N. Wolff. How stagnant are services? In Jeand Gadrey and Faïz Gallouj, editors, Productivity, Innovation and Knowledge in Services, chapter 1, pages 3-25. Edard Elgar, 2002.

[52] Peter Wood. A service-oriented approach to regional innovationor adaptation? The Service Industries Journal, 25(4):429-445, 2005. 


\begin{tabular}{|c|c|c|}
\hline Parameter & Description & Value \\
\hline$\mu$ & markup & 0.3 \\
\hline$b$ & Threhold for replacement investment in $\mathrm{K}$ goods & 8 \\
\hline$\zeta_{1}$ & $\begin{array}{l}\text { Power of the competitivity index for } \mathrm{K} \text { goods and KIBS } \\
\text { sectors }\end{array}$ & 1 \\
\hline$\zeta_{2}$ & $\begin{array}{l}\text { Power of the competitivity index for consumption goods } \\
\text { and services sectors }\end{array}$ & 1 \\
\hline$\beta$ & Sensibility to errors of expectations & 0.5 \\
\hline$\eta$ & $\begin{array}{l}\text { Scale parameter used in the innovation process of the } \mathrm{K} \\
\text { good suppliers }\end{array}$ & 0.01 \\
\hline$\gamma$ & $\begin{array}{l}\text { Share of their sales invested by the } K \text { good suppliers in } \\
\text { R\&D }\end{array}$ & 0.5 \\
\hline$\vartheta_{\min }$ & $\begin{array}{l}\text { Minimum share of their budget that consumers use for } \\
\text { buying services }\end{array}$ & 0.1 \\
\hline$\vartheta_{\text {min }}$ & $\begin{array}{l}\text { Maximum share of their budget that consumers use for } \\
\text { buying services }\end{array}$ & 0.8 \\
\hline$\iota$ & $\begin{array}{l}\text { Scale parameter used in the Engel's law (see equation } \\
14\end{array}$ & 0.5 \\
\hline$k$ & $\begin{array}{l}\text { Maximum level of the Debt/Sales ratio for obtaining a } \\
\text { loan }\end{array}$ & 2 \\
\hline$A$ & Maximum number of periods for repaying a loan & 10 \\
\hline$\kappa$ & $\begin{array}{l}\text { Maximum impact of a knowledge investment on the pro- } \\
\text { ductivity of an industrial firm }\end{array}$ & 0.5 \\
\hline$\kappa_{\text {Services }}$ & $\begin{array}{l}\text { Maximum impact of a knowledge investment on the pro- } \\
\text { ductivity of a service firm }\end{array}$ & 0.25 \\
\hline$\Theta$ & $\begin{array}{l}\text { Share of their capital goods that each consumer good } \\
\text { firm compares with the newest machines available on } \\
\text { the K goods market }\end{array}$ & 0.5 \\
\hline
\end{tabular}

Table 2: Parameters of the reference scenario 


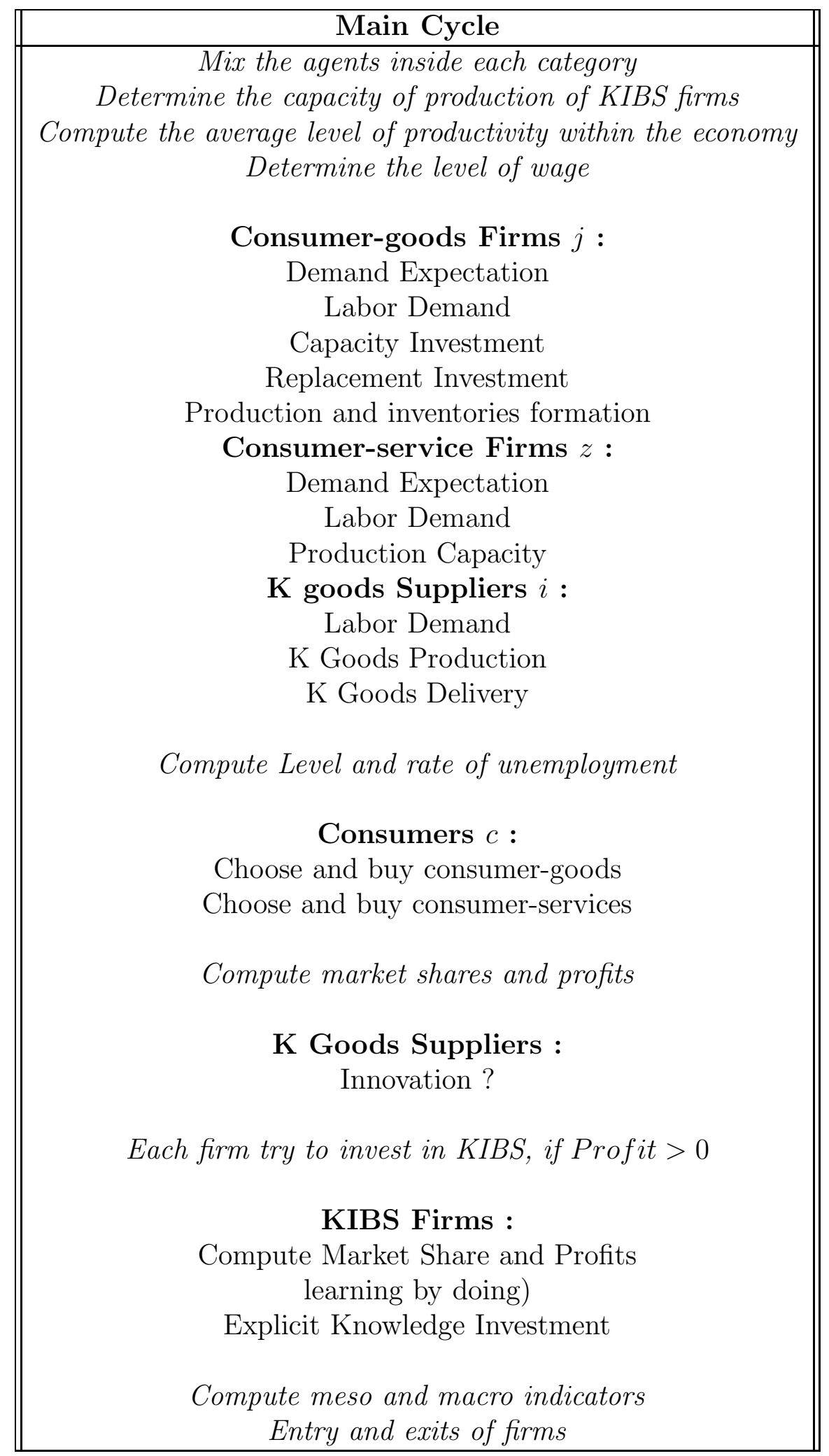

Table 3: Main cycle of 28 the agent-based system 


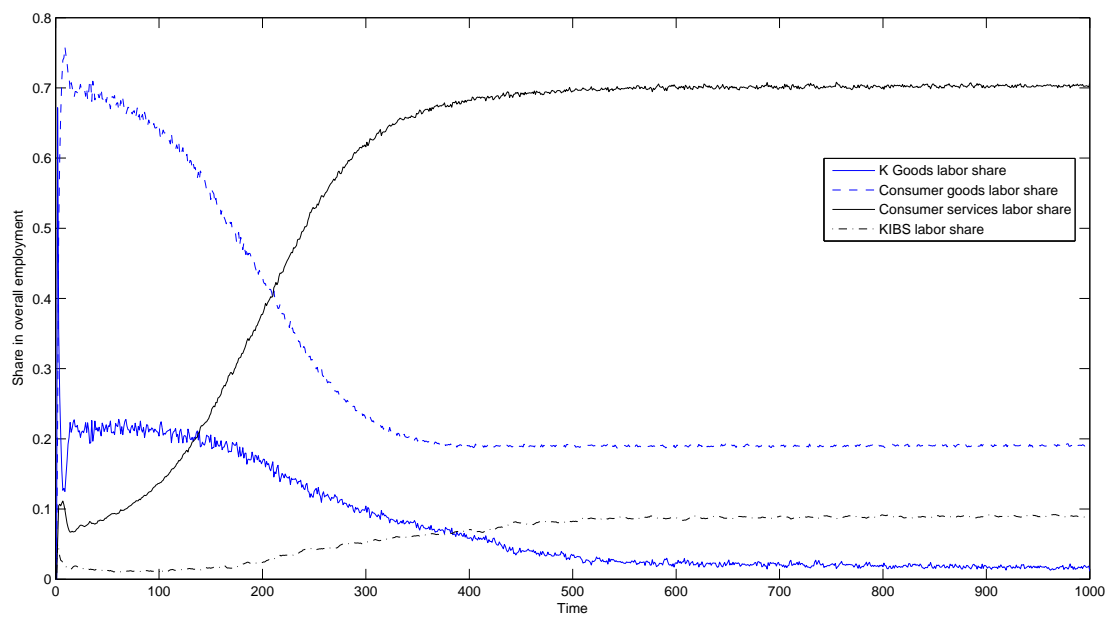

(a)

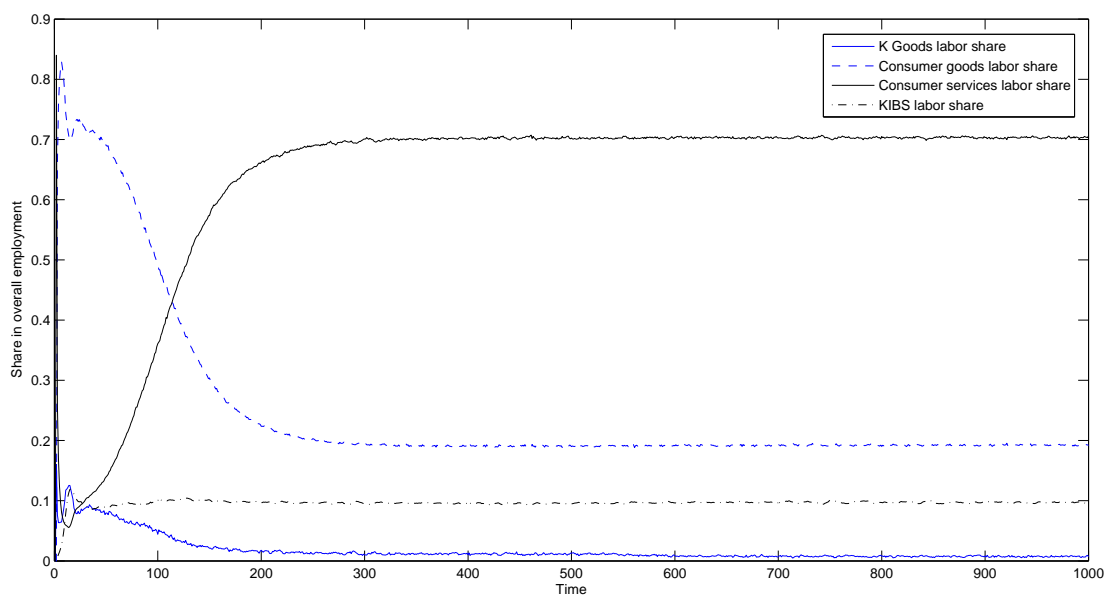

(b)

Figure 3: General process of structural change in employment (a) with $\Theta=$ 0.5 , (b) with $\Theta=0.1$ 
Figure 4: Sectoral levels of labor productivity over time

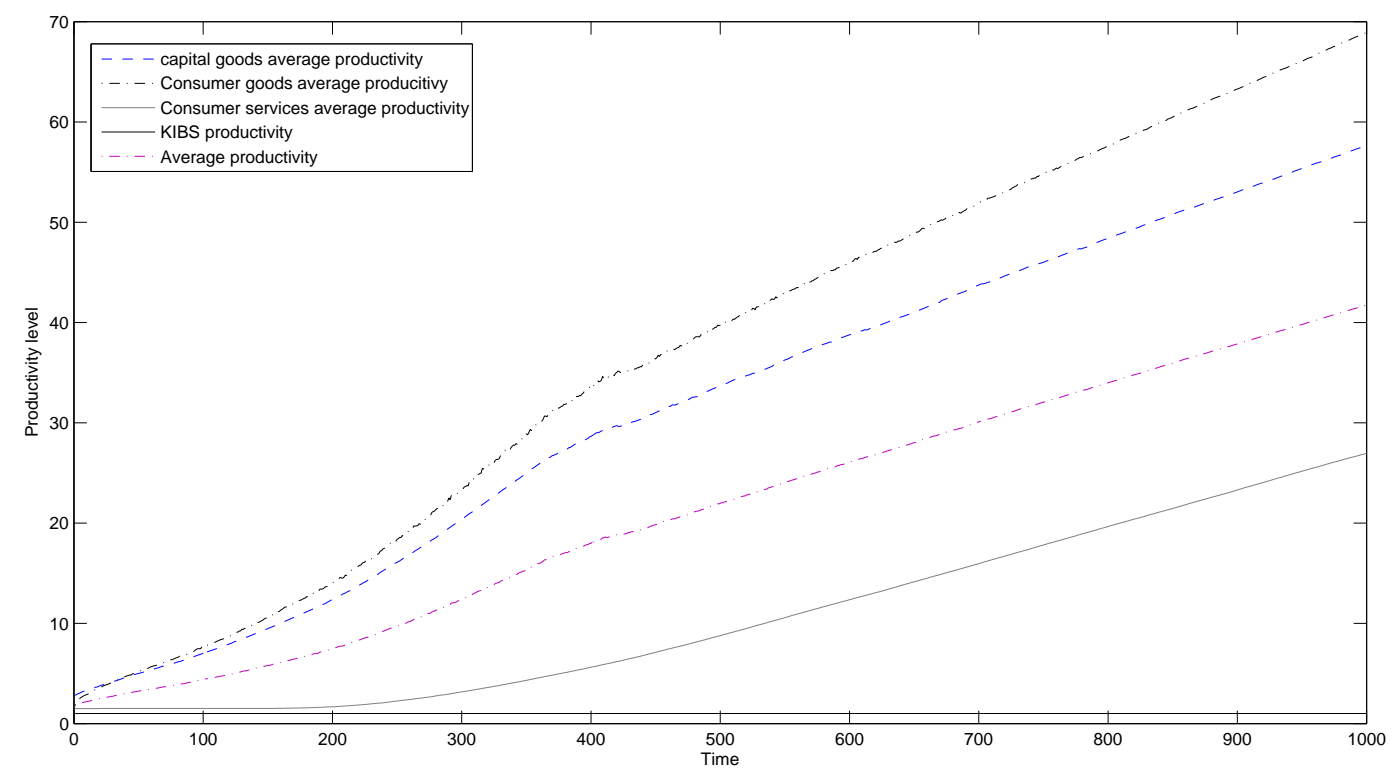



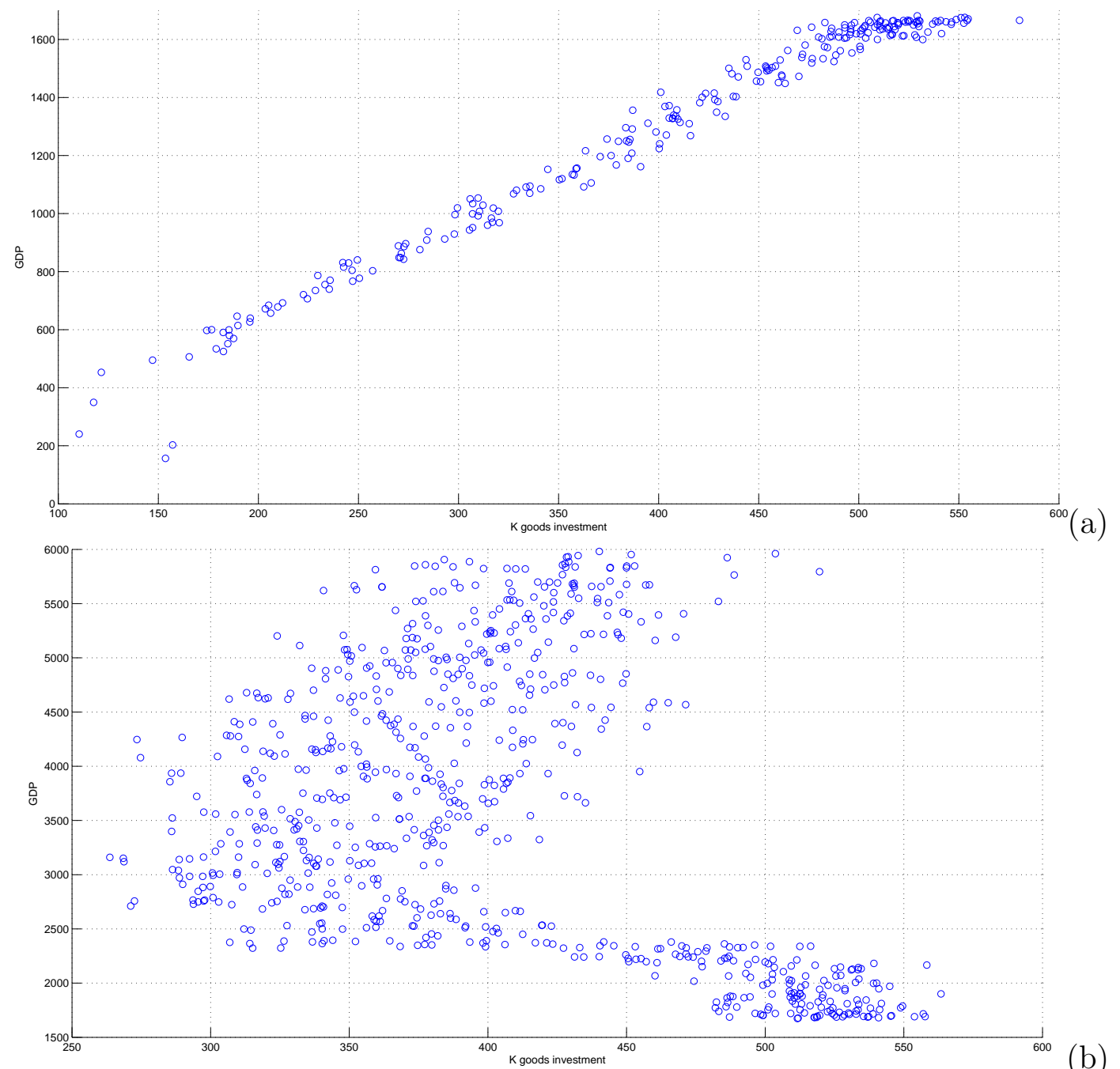

Figure 5: K goods investment VS level of GDP, (a) with $t \in[0 ; 250]$, (b) with $t \in[251 ; 1000]$ 
Figure 6: Average level of knowledge, $H$, VS the level of GDP

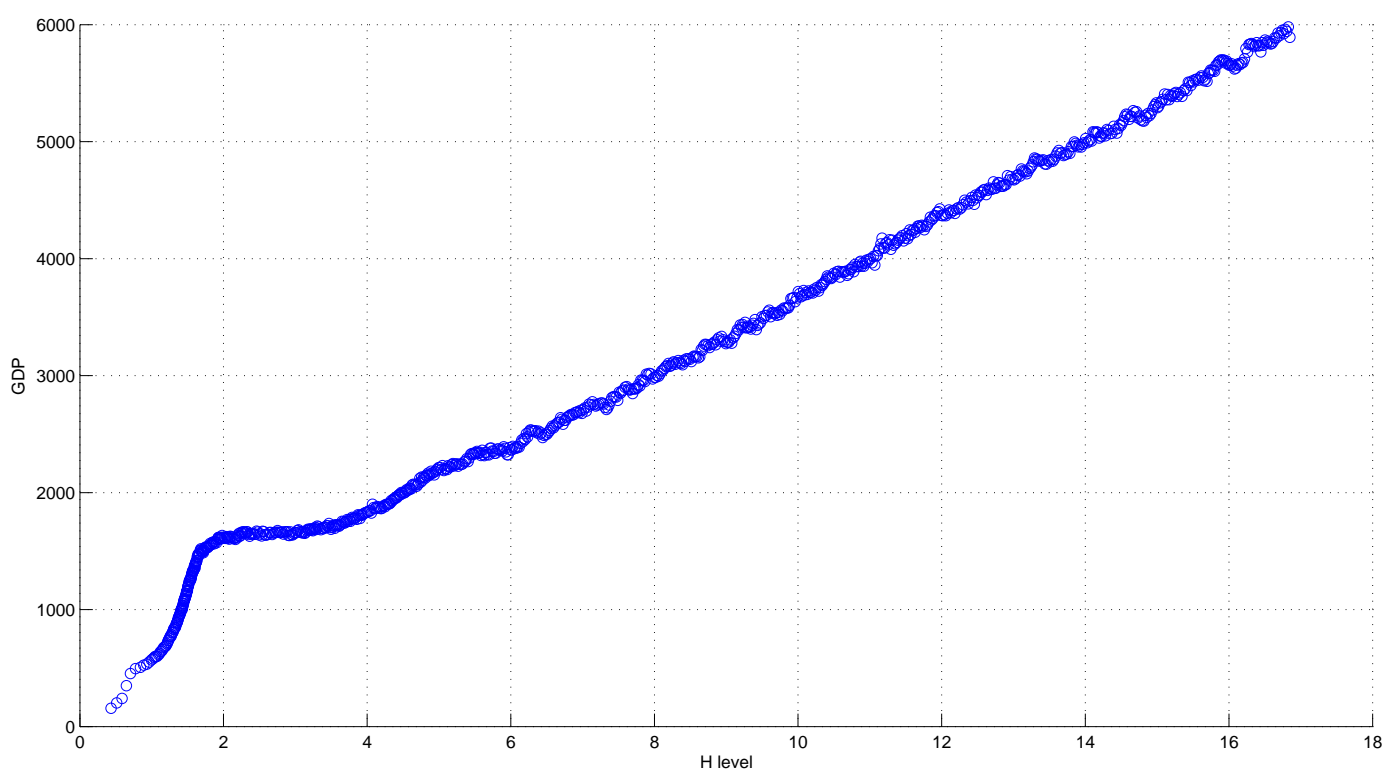




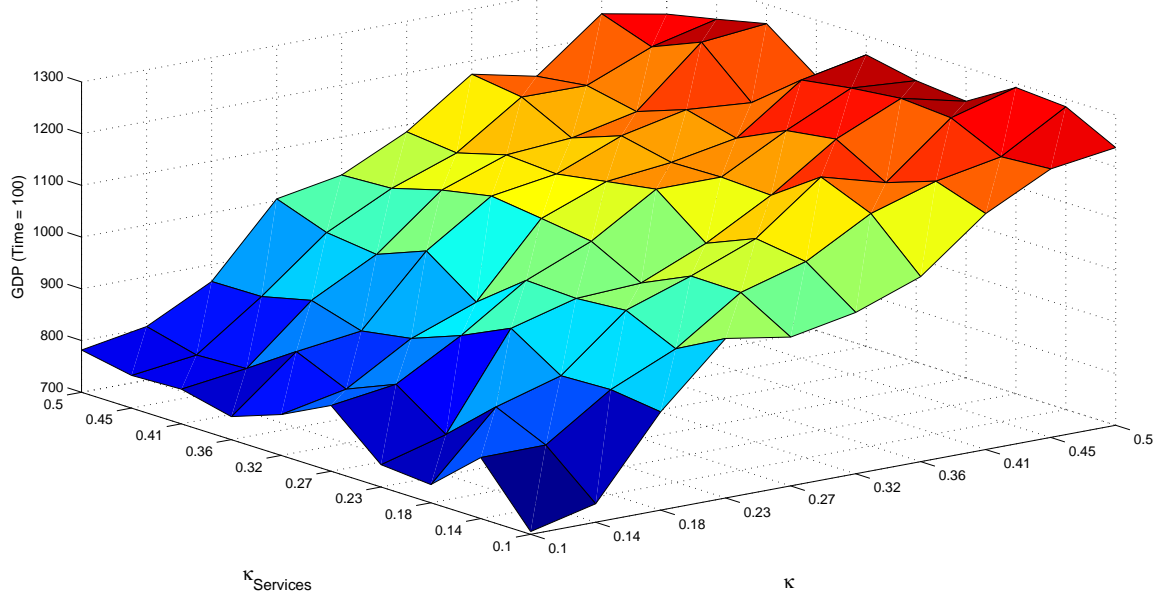

(a)

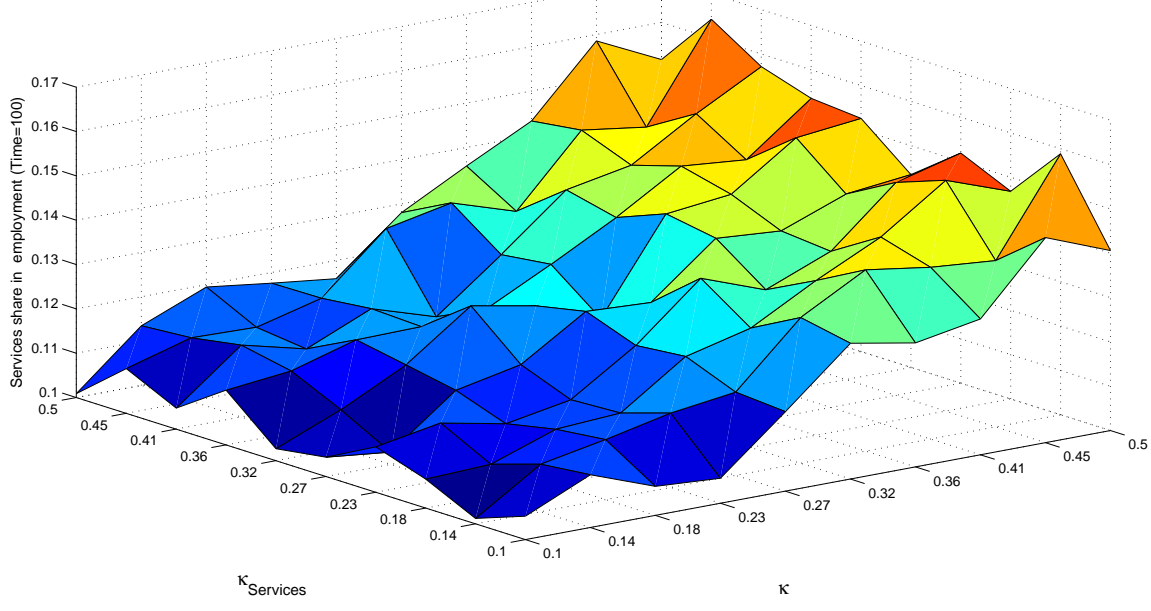

Figure 7: Impact of $\kappa$ and $\kappa_{\text {Services }}$ parameters for $t=100$, (a) on the level of GDP, (b) on the overall share of services (KIBS and consumer services) in employment. 


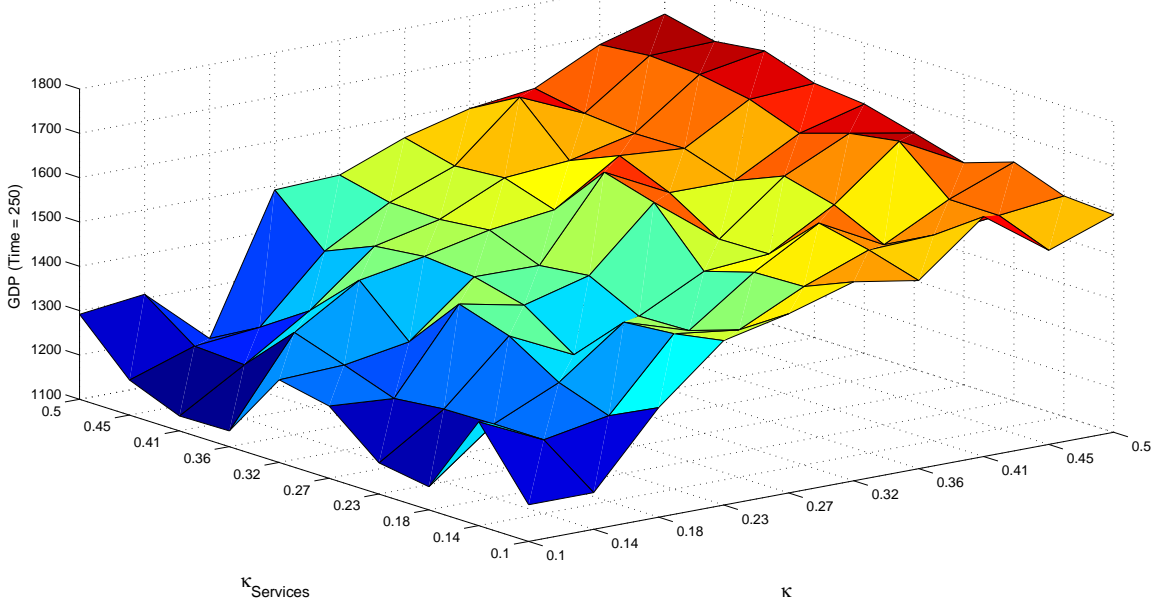

(a)

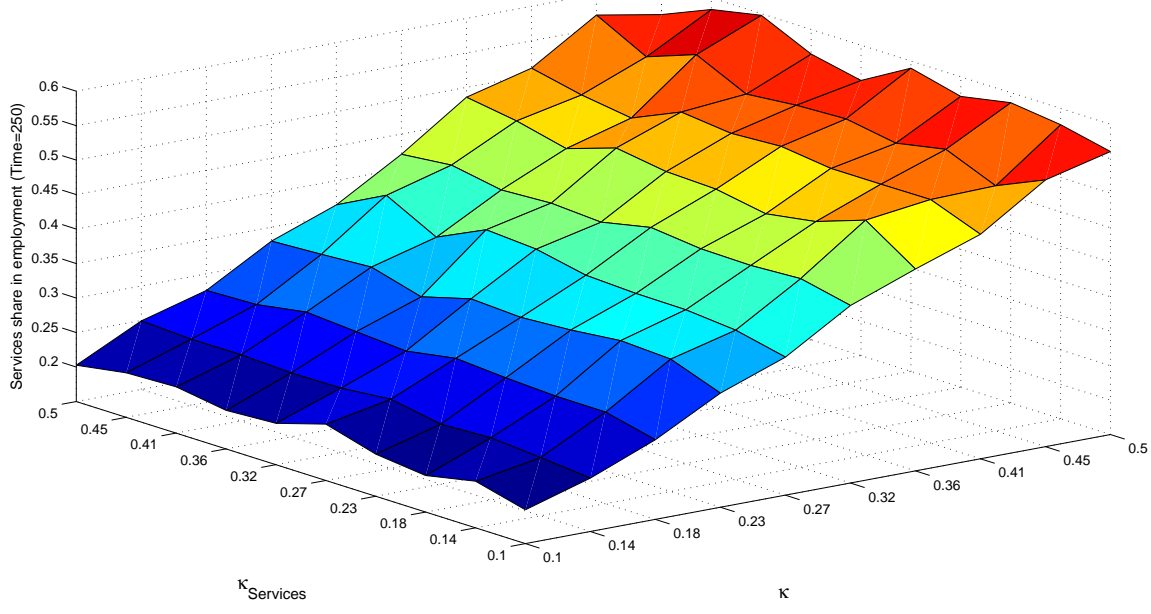

Figure 8: Impact of $\kappa$ and $\kappa_{\text {Services }}$ parameters for $t=250$, (a) on the level of GDP, (b) on the overall share of services (KIBS and consumer services) in employment. 


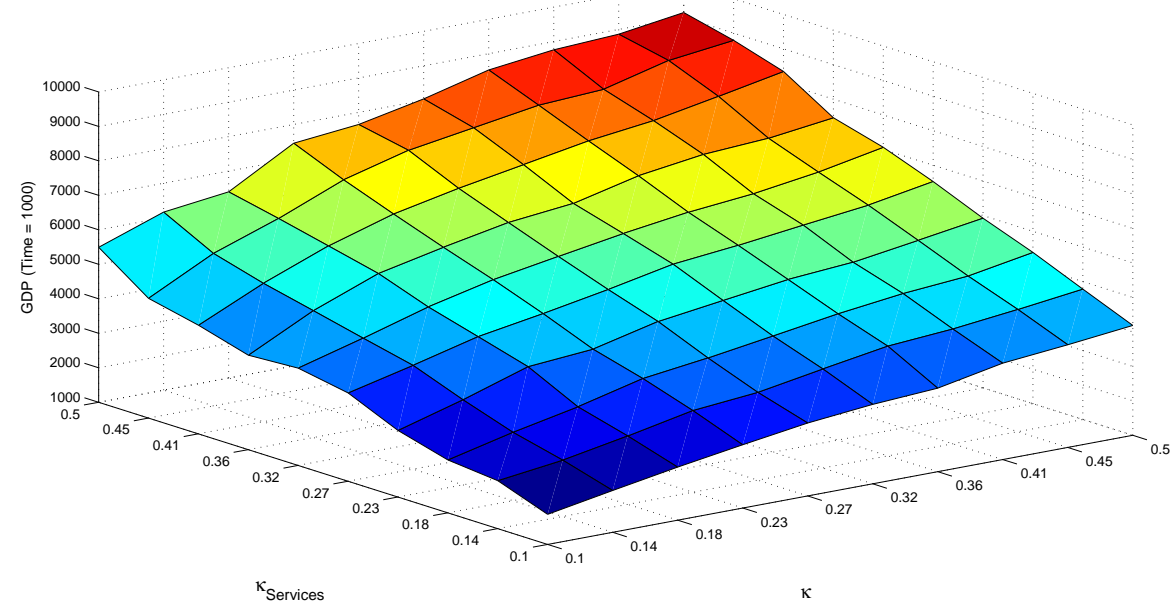

(a)

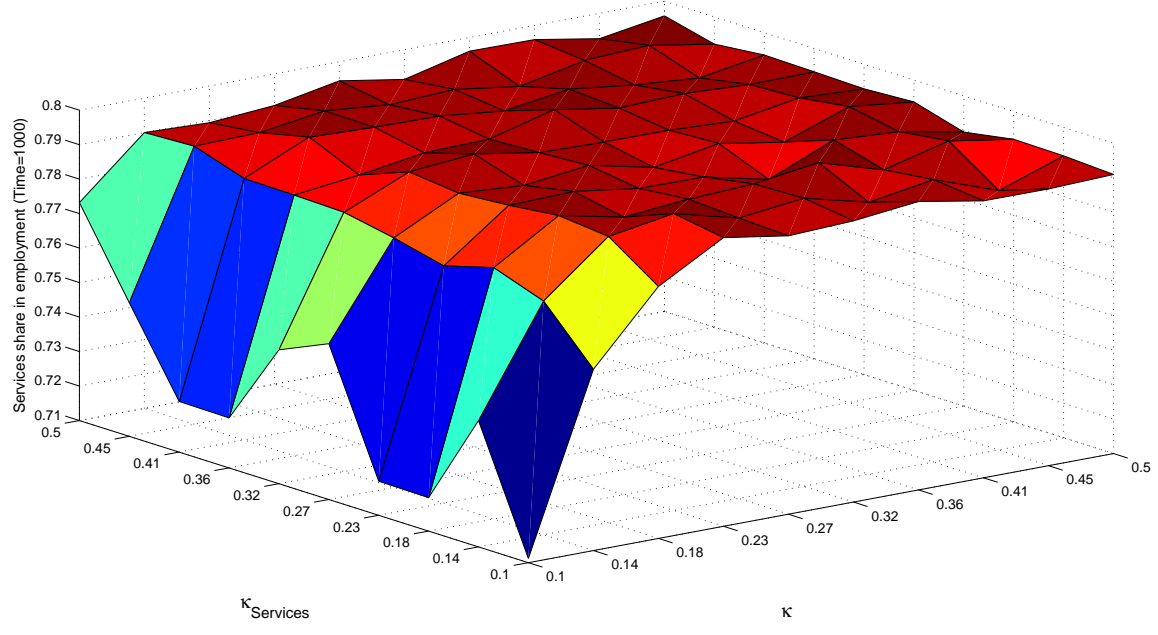

Figure 9: Impact of $\kappa$ and $\kappa_{\text {Services }}$ parameters for $t=1000,(\mathrm{a})$ on the level of GDP, (b) on the overall share of services (KIBS and consumer services) in employment. 


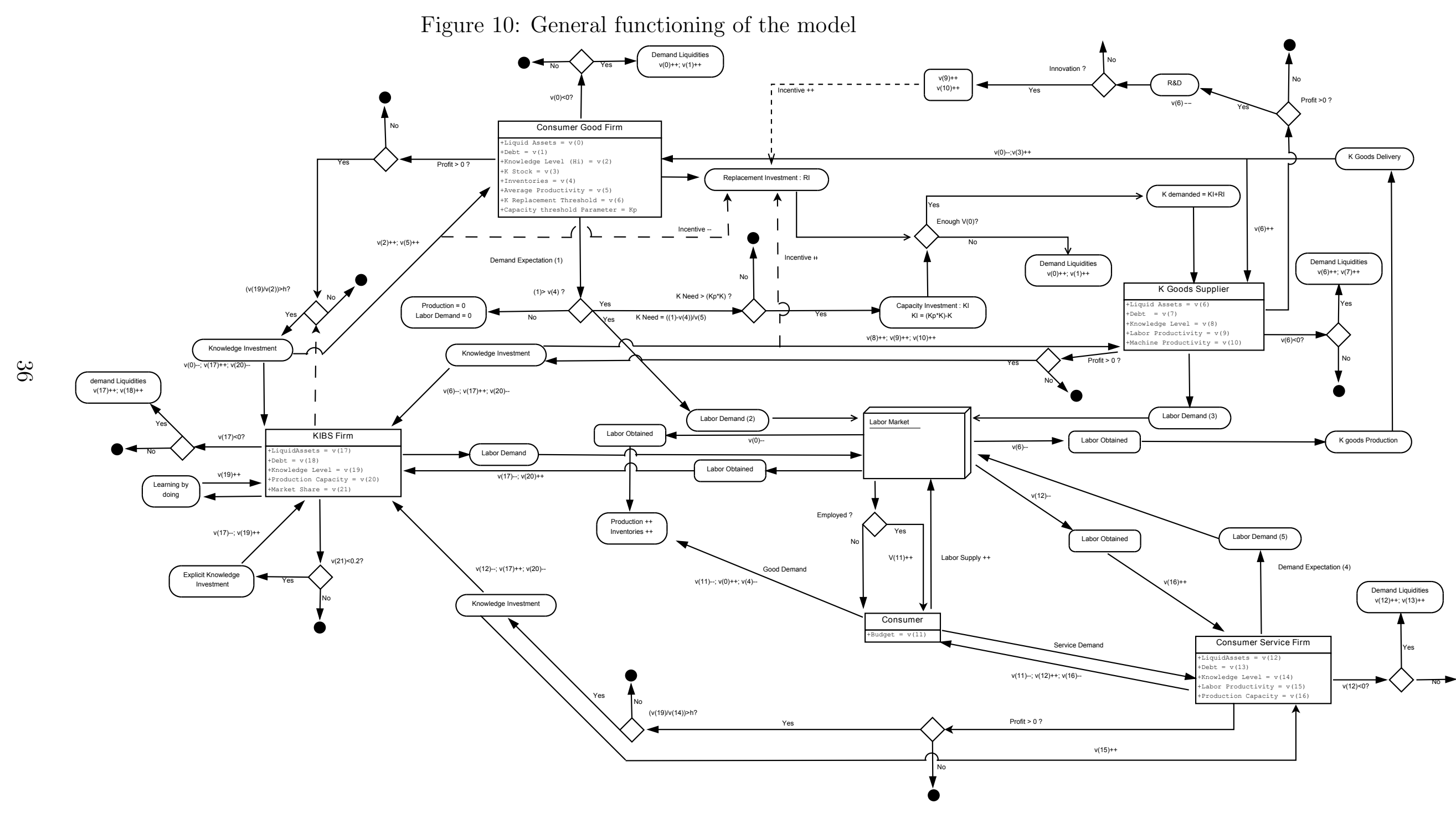

